DOI: 10.12731/2658-4034-2020-2-69-72

\title{
О НЕКОТОРЫХ ХАРАКТЕРИСТИКАХ КОНФЛИКТОВ В ОРГАНИЗАЦИЯХ
}

\section{Преображенский А.П. ${ }^{1}$, Чопоров О.Н. ${ }^{2}$}

${ }^{1}$ Воронежский институт высоких технологий,

г. Воронеж, Российская Федерация

${ }^{2}$ Воронежский государственный технический университет,

г. Воронеж, Российская Федерация

В данной работе проведен анализ особенностей характеристик конфликтов, которые могут возникать в организациях. Обсуждаются возможные подходы для описания конфликтов.

Ключевые слова: конфликт; организация; модель; характеристика.

\section{ABOUT SOME CHARACTERISTICS OF CONFLICTS IN ORGANIZATIONS}

\author{
Preobrazhenskiy A.P. ${ }^{1}$, Choporov O.N. ${ }^{2}$ \\ ${ }^{1}$ Voronezh Institute of High Technologies, \\ Voronezh, Russian Federation \\ ${ }^{2}$ Voronezh State Technical University, \\ Voronezh, Russian Federation
}

This paper analyzes the characteristics of the characteristics of conflicts that may arise in organizations. Possible approaches to describing conflicts are discussed.

Keywords: conflict; organization; model; characteristic.

\section{Введение}

Конфликты могут наблюдаться в различных областях. В современных условиях их роль возрастает вследствие того, что они влияют на экономическое развитие организаций, бытовые отношения, политическое развитие и т.д. Изучение конфликтов в организациях 
важно вследствие необходимости решения целого комплекса проблем $[1,2]$. В данной работе рассматриваются некоторые характеристики конфликтов внутри компаний.

\section{Характеристики конфликтов внутри организаций}

Для конфликтов, как отмечают некоторые исследователи, характерна устойчивость. Это связано с инерционностью процессов, происходящих внутри организаций. В таких случаях даже стремление найти окончание конфликта не всегда бывает сразу успешным. Это происходит вследствие того, что трудно вести поиск компромиссов и есть определенная ограниченность по знаниям [3].

Другой характерной особенностью конфликтов внутри компаний является то, что они далеко не всегда являются предсказуемыми. Происходит это вследствие того, что в основе конфликтов лежат случайные явления, а не детерминированные. Для детерминированных процессов возможности прогнозирования являются более широкими. Но и описание конфликтов только на основе вероятностного подхода можно считать неправильным.

Объяснить это можно тем, что образование форм конфликтов будет происходить в ходе самих процессов взаимодействия субъектов внутри организаций. То есть, при описании используют понятие неопределенности, которая будет содержать внутри себя случайности лишь только как некоторые компоненты $[4,5]$.

Например, внутри организации, если возникает конфликт, то его участники не будут владеть полной информацией по противоположной стороне. Тогда говорят о такой характеристике, как незнание.

Достоверные оценки в ходе конфликта весьма сложно получить, что ведет к появлению неизвестности.

У каждого из участников конфликта можно отметить свои метрики величин, которые трудно поддаются стандартизации и унификации. Тогда говорят о такой характеристике как несоизмеримости.

Сама конфликтная обстановка со стороны участников рассматривается неадекватным образом. Это ведет и к неадекватному поведению. 
То есть, для конфликтов характерна полифуркационность. Процессы ветвления осуществляются по самым различным траекториям. Это ведет к слабой предсказуемости.

Даже если есть определенный уже собранный опыт по конфликтам внутри организаций, это нельзя рассматривать как полноценную основу для того, чтобы в рамках текущих конфликтов осуществлять соответствующие рациональные шаги по выбору.

То есть, необходимо воспринимать информацию по советам извне, но в дальнейшем важно основываться на собственном здравом смысле и соображениях.

Трудно осуществлять принуждению обе стороны к погашению конфликтной ситуации. Это можно рассматривать как неэтичные и неправомерные действия.

В конфликтах, происходящих внутри организациях, присутствует также риск. При этом его описание отличается от классического представления, поскольку нет возможностей для того, чтобы дать точную оценку по опасности. Выделяют оперативные, ситуационные и вероятностные риски. Первые связаны с предвидениями, вторыес возможностями отклонения от первоначальных оценок, третьи - с сопоставлением априорных вероятностей исходов.

\section{Выводы}

Проведенный анализ показал, что изучение конфликтов должно базироваться на том, что вскрываются внутренние закономерности того, какие колебания возникают внутри организаций, Они приводят или к квазиколебаниям или разрушениям систем. Для их описания требуется построение соответствующих моделей.

\section{Список литературы}

1. Мельникова Т.В. Особенности психологического воздействия и принципа авторитета // В книге: Конвергенция естественнонаучного и гуманитарного знания тезисы докладов Международной научной школы-конференции «Естественнонаучные методы исследований в гуманитарных и социальных науках». 2018. С. 31. 
2. Цуберт Е.К., Козлов В. Организационная культура в малом бизнесе // Вестник Воронежского института высоких технологий. 2015. № 2 (15). C. 220-222.

3. Китаева К.А. Психологический анализ чувства любви // В мире научных открытий. 2010. № 4-2 (10). С. 71-72.

4. Максимова И.В., Ваганова О.И., Карпова М.А. Использование видеофрагментов при преподавании дисциплин естественнонаучного цикла // Современные исследования социальных проблем (электронный научный журнал). 2018. Т. 9. № 9-2. С. 56-59.

5. Якушева С.Д. Самоменеджмент в деятельности педагога современного образовательного комплекса // Современные исследования социальных проблем (электронный научный журнал). 2018. Т. 9. № 11. C. $242-263$.

\section{References}

1. Mel'nikova T.V. Osobennosti psihologicheskogo vozdejstviya i principa avtoriteta // V knige: Konvergenciya estestvennonauchnogo i gumanitarnogo znaniya tezisy dokladov Mezhdunarodnoj nauchnoj shkoly-konferencii «Estestvennonauchnye metody issledovanij v gumanitarnyh i social'nyh naukah». 2018. S. 31.

2. Cubert E.K., Kozlov B. Organizacionnaya kul'tura v malom biznese // Vestnik Voronezhskogo instituta vysokih tekhnologij. 2015. № 2 (15). S. 220-222.

3. Kitaeva K.A. Psihologicheskij analiz chuvstva lyubvi // V mire nauchnyh otkrytij. 2010. № 4-2 (10). S. 71-72.

4. Maksimova I.V., Vaganova O.I., Karpova M.A. Ispol'zovanie videofragmentov pri prepodavanii disciplin estestvennonauchnogo cikla // Sovremennye issledovaniya social'nyh problem (elektronnyj nauchnyj zhurnal). 2018. T. 9. № 9-2. S. 56-59.

5. Yakusheva S.D. Samomenedzhment v deyatel'nosti pedagoga sovremennogo obrazovatel'nogo kompleksa // Sovremennye issledovaniya social'nyh problem (elektronnyj nauchnyj zhurnal). 2018. T. 9. № 11. S. 242-263. 